\title{
Coherence in Hong Lou Meng and its English translations: an exploratory investigation
}

\author{
Xi Li id and Canzhong Wu
}

\author{
* Correspondence: \\ xili.celia@hotmail.com \\ Department of Linguistics, \\ Macquarie University, New South \\ Wales 2109, Sydney, Australia
}

\begin{abstract}
Coherence can be studied from both logical and textual perspectives in systemic functional linguistics. The logical and textual metafunctions together contribute to the coherence of a text. Coherence is realized through clause complexes and cohesive chains at the lexicogrammatical level from the logical and textual meanings. Clause complex reflects the logical development of the text, while cohesive chains are the threads of a coherent text. The clauses that are involved in cohesive chains take a more important role in forming a coherent text than others, and thus have the potential to reveal the features of coherence realization.

This research aims to explore the realization of coherence in a Chinese novel Hong Lou Meng and its two English translations, The Dream of the Red Mansions (by Yang Xianyi and Gladys Yang) and The Story of the Stone (by David Hawkes), or more specifically, the distribution of logico-semantic types in both the Chinese (ST) and the English texts (TT). The research shows that there are both similarities and differences between the ST and the Tाs on the one hand, and between the Ts on the other, and that the differences are related to the styles of translators.
\end{abstract}

Keywords: Coherence, Realization of coherence, Clause complex, Cohesive chains, Translation, Chinese and English texts

\section{Introduction}

Coherence has been the focus of text linguistics for a few decades (e.g. Hasan, 1985; Seidlhofer and Widdowson 1999; Taboada 2004); however, there has been little research on coherence in Chinese-English translation from functional linguistic perspectives. Chinese and English are two quite different languages, with their own ways of construing coherence. Zhang (2012, p. 272) claims that “"[c]oherence is the essential condition to distinguish text from non-text", so being coherent is the basic characteristic of a source text which can be understood and translated into another language. In this research, the Chinese source and English target texts are coherent in nature. The object of study is therefore not whether they are coherent or not, or to what extent they are coherent, but how they differ in realizing coherence.

The present research chooses the perspective of coherence from a systemic functional linguistic view as the entry point to compare a source Chinese text and its two English translations, so as to illuminate the differences in the realization of coherence

(c) The Author(s). 2017 Open Access This article is distributed under the terms of the Creative Commons Attribution 4.0 International License (http://creativecommons.org/licenses/by/4.0/), which permits unrestricted use, distribution, and reproduction in any medium, provided you give appropriate credit to the original author(s) and the source, provide a link to the Creative Commons license, and indicate if changes were made. 
in both the Chinese source text and the English target texts and how coherence is kept and achieved in translation. It is necessary to examine the feasibility of systemic functional linguistics applied in analysing the realization of coherence in both Chinese and English. One benefit of systemic functional linguistics is that it can provide an overall view of different languages, and can describe both Chinese and English texts from a multi-dimensional view. The description can therefore set the two language texts in the same framework, which provides a basis for a comparative study. To compare the ways that the source and target texts realize coherence, the study will elaborate how the two English target texts handle the transference of coherence and how they are different from the Chinese source text and from each other based on the different properties of systemic functional linguistics.

Since this study aims to provide a perspective on distinguishing the realization of coherence and also coherence in translation, a highly operational and plausible model of analysing textual coherence needs to be set up to make the results practical, comprehensive and reliable. The model should be able to depict characteristics of coherence both in the Chinese ST and English TTs. Research on coherence can be applied in translation studies.

\section{Coherence}

Coherence is referred as the property of "unity" and of "hanging together" (Hasan 1984, p. 181). The study of coherence is always closely related to cohesion. According to Halliday and Hasan (1985 [1989], p. 94), "cohesion is the foundation on which the edifice of coherence is built", and "the basis for textual coherence lies in cohesion" (Hasan 1984, p. 210). In the present research, cohesion is treated as a key factor in building up coherence of the text. Cohesion is considered as "the aspect of texture which upholds textuality by making a sequence of sentences hang together as a coherent text" (Hatim \& Mason, 1990, p. 210). The cohesive chains serve to connect the units of text, and are taken as threads of semantic sequence of the text. In order to determine how cohesion contributes to coherence, cohesive chains are the focus of this research.

Different views on coherence from the functional linguistic approach are presented and framed in Table 1 in the Function-Rank Matrix, to present, categorise and relate the previous research views on coherence.

The purpose of the present research is to develop a model for coherence analysis capable of generating a framework for describing coherence in Chinese and English texts and also in translation.

As shown in Table 1, coherence is the collective effect of the different metafunctions. It can be probed from different perspectives in the systemic functional framework. Since lexicogrammar is the core of the language (Halliday 1984), coherence is realized in lexicogrammar through different systems in different metafunctions.

\section{The theoretical framework for the study of coherence}

Coherence in SFL framework is defined as the property of "unity" and "hanging together" (Hasan 1984, p. 181). Given the property, coherence is studied from logical and textual metafunctions in the present research. The logical metafunction is realized by paratactic and hypotactic complexes at different ranks, with one of these, the clause rank, being the focus of this research. The textual metafunction is realized by cohesion 
Table 1 Previous definition and studies of coherence framed in the Function-Rank Matrix

\begin{tabular}{|c|c|c|c|c|c|}
\hline & & \multicolumn{2}{|l|}{ Ideational } & \multicolumn{2}{|l|}{ Textual } \\
\hline & & Experiential & Logical & & \\
\hline & & & & \multicolumn{2}{|c|}{$\begin{array}{l}\text { Cohesion (Halliday and } \\
\text { Hasan 1976) foundation of } \\
\text { coherence }\end{array}$} \\
\hline & & & & $\begin{array}{l}\text { Structure } \\
\text { cohesion }\end{array}$ & $\begin{array}{l}\text { Non- } \\
\text { structure } \\
\text { cohesion }\end{array}$ \\
\hline \multirow[t]{9}{*}{ Context } & $\begin{array}{l}\text { Widdowson } \\
\text { (1978) }\end{array}$ & & $\begin{array}{l}\text { van Dijk \& Kintsch } \\
(1978 ; 1983)\end{array}$ & \multicolumn{2}{|c|}{$\begin{array}{l}\text { Reinhart (1980) } \\
\text { connectedness (cohesion); } \\
\text { consistency and relevance } \\
\text { (theme, their relation with } \\
\text { the context) }\end{array}$} \\
\hline & $\begin{array}{l}\text { Hasan (1978) } \\
\text { Generic Structure } \\
\text { Potential (GSP) }\end{array}$ & & & & \\
\hline & $\begin{array}{l}\text { Beaugrande and } \\
\text { Dressler (1981) }\end{array}$ & & $\begin{array}{l}\text { Garrod and } \\
\text { Doherty (1995) } \\
\text { (cognitive) }\end{array}$ & & \\
\hline & $\begin{array}{l}\text { van Dijk (1985), } \\
\text { p. } 111\end{array}$ & & Widdowson (2007), p. 51 & & \\
\hline & $\begin{array}{l}\text { Giora (1985) } \\
\text { hyper theme }\end{array}$ & & & & \\
\hline & $\begin{array}{l}\text { Campbell (2013), } \\
\text { p. } 5\end{array}$ & & & & \\
\hline & $\begin{array}{l}\text { Eggins (1994), } \\
\text { p. } 87\end{array}$ & & & & \\
\hline & $\begin{array}{l}\text { Seidlhofer and } \\
\text { Widdowson } \\
\text { (1999), p. } 207\end{array}$ & & & & \\
\hline & Taboada (2004) & & & & \\
\hline \multirow[t]{6}{*}{ Semantics } & $\begin{array}{l}\text { van Dijk (1977), } \\
\text { p. } 33\end{array}$ & & $\begin{array}{l}\text { Mann, Matthiessen } \\
\text { \& Thompson } \\
\text { (1987; 1989) } \\
\text { RST }\end{array}$ & $\begin{array}{l}\text { Danes (1974) } \\
\text { thematic } \\
\text { progression }\end{array}$ & $\begin{array}{l}\text { Hasan } \\
\text { (1984) } \\
\text { cohesive } \\
\text { harmony }\end{array}$ \\
\hline & van Dijk (1985) & & Huang (1988) & & $\begin{array}{l}\text { Tierney and } \\
\text { Mosenthal } \\
\text { (1983) }\end{array}$ \\
\hline & & & $\begin{array}{l}\text { Knott and Dale } \\
(1994) \\
\text { computational } \\
\text { linguistics }\end{array}$ & \multicolumn{2}{|l|}{$\begin{array}{l}\text { Werth (1984), } \\
\text { p. } 73\end{array}$} \\
\hline & & & Harabagiu (1999) & & $\begin{array}{l}\text { Lorentz } \\
\text { (1999) }\end{array}$ \\
\hline & & & $\begin{array}{l}\text { Sanders \& } \\
\text { Noordman (2000) } \\
\text { (cognitive) }\end{array}$ & & $\begin{array}{l}\text { Tanskanen } \\
(2006)\end{array}$ \\
\hline & & & $\begin{array}{l}\text { Wolf and Gibson } \\
(2006)\end{array}$ & & \\
\hline Lexicogrammar & & $\begin{array}{l}\text { Zhang } \\
\text { (1999) }\end{array}$ & $\begin{array}{l}\text { Neubert and } \\
\text { Shreve (1992), } \\
\text { p.94 }\end{array}$ & & \\
\hline Phonology & & & & & \\
\hline
\end{tabular}


around the clause (Halliday and Matthiessen 2004). The realization of coherence can be studied in terms of the lexicogrammatical patterns of logical and textual metafunctions.

Logically, the lexicogrammatical patterns are manifested by clause complexes. The clause complex analysis in the present research is a basis for showing how the links between the segments of text create a logically connected whole, and thus contribute to the overall coherence of the text. Additionally, the logical meaning "is composed of the functional and semantic relations that make up the logic of natural language" (Halliday 1994, p. 216). The recursive feature of the logical meanings forms the rationale that the logical metafunction can induce logical development through the recursion of the paratactic and hypotactic relations, and "set up logical-semantic relationships between one clausal unit and another" (Halliday 2003). In meaning construction, the clause is regarded grammatically as the basic unit. However, in the text, the unit construing meaning is often at the rank above the clause, which is the clause complex: "When a number of clauses are linked together grammatically, we talk of a clause complex (each single linkage within a clause complex can be referred to as one clause nexus)" (Halliday and Matthiessen 2004, p. 4). Figure 1 shows how the clauses combine to form a clause complex with the two subsystems, TAXIS and LOGICO-SEMANTIC TYPE, and also the recursion of these two subsystems.

The textual metafunction also plays a significant role in the creation of coherence, as stated by Lukin (2013): "It is the textual function which does the textmaking work" (p. 524). According to Hasan (1984), "the basis for textual coherence lies in cohesion" (p. 210), and "Cohesion is an essential property of texts, but it is the way the cohesive resources are deployed that makes the difference between text and non-text, and between one text and another" (Halliday and Hasan 1985 [1989], p. 54). In the present research, cohesion is treated as a key factor in building up the coherence of a text, and the configuration of cohesive devices in cohesive chains in the text as essential. The logical relations between clauses realize the logical development of a text; and the clauses with cohesive devices in cohesive chains make the overall texture of a text recognizable. The outline of the cohesive chains establishes the structure of cohesion upon which the textual coherence arises; and the cohesive devices in these cohesive chains are important in forming the grid of cohesion structure. Hence, in the construction of coherence, the clauses with those cohesive devices are more significant than those clauses without the cohesive devices.

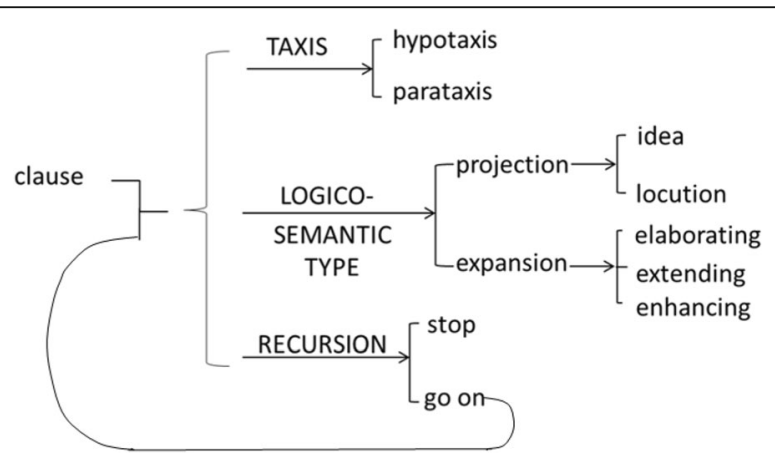

Fig. 1 The system of clause complexing (Halliday and Matthiessen 2004, p. 373) 
Considering the above elements in the creation of coherence, Table 2 specifies the location of the present research in bold in the systemic functional linguistic framework. Thus, the mutual effect that the logical and textual meaning has on the construction of coherence can be investigated in terms of clause complex and cohesion of the text. Since cohesive chains are taken as the basis of coherence, the interrelation of the logical and textual meanings can tell us how the cohesive devices and clauses make a coherent text, and how they are representative in distinguishing the coherence of a text. Therefore, in the output of coherence, the logical and textual meanings are both included in the description, which can give us an idea of how the coherent text works with the relevant tokens and logical relations.

\section{Data and research methods}

The data used in this research come from one of the four Chinese classic novels Hong Lou Meng (abbreviated as HLM) and its two well-recognized English translated versions, The Dream of the Red Mansions (translated by YangXianyi and polished by Gladys Yang, 1994), hereafter referred as target text 1 (TT1); and The Story of the Stone (translated by David Hawkes, 1973), hereafter referred as target text 2 (TT2). This novel has 120 chapters altogether, but only three chapters are selected for study in this research as an exploratory investigation, establishing a basis for a comprehensive, largescale study of the whole novel down the track.

For this purpose, Chapter 1, 2, and 39 are chosen, with the original text having 19,134 Chinese characters, and the translations having 14,034 and 19,057 words respectively. As it is the lexicogrammar that is the object of study, all the texts are firstly divided into clause complexes, which are then divided into clauses. Secondly, all the grammatical and lexical cohesive devices of each text are annotated, with identity chains (IC) and similarity chains (SC) identified. Thirdly, all clause complexes in each text are analysed in terms of LOGICO-SEMANTIC RELATIONS and TAXIS. Finally, the construction of coherence is examined with respect to cohesive chains and clause complexity between the source text and the target texts on the one hand, and between the two target texts on the other.

\section{Analysis and results}

As stated before, the construction of coherence is related to the logical and textual meanings of a text. The analysis of cohesive chains and clause complexity reveals the patterns of realizing coherence in the text.

Table 2 The location of current study in stratification-metafunction matrix

\begin{tabular}{|c|c|c|c|c|}
\hline \multirow[b]{3}{*}{ Stratum } & \multicolumn{4}{|c|}{ Metafunction } \\
\hline & \multicolumn{2}{|l|}{ Ideational } & \multirow[t]{2}{*}{ Textual } & \multirow[t]{2}{*}{ Interpersonal } \\
\hline & Experiential & Logical & & \\
\hline Semantics & & & Cohesion & \\
\hline Lexicogrammar & & Clause complex & Cohesive chains & \\
\hline
\end{tabular}


Table 3 An excerpt from $\Pi 2$

\begin{tabular}{|c|c|c|c|c|c|c|}
\hline $\begin{array}{l}\text { Clause } \\
\text { ID } \\
\end{array}$ & Clause & $\begin{array}{l}\text { Cohesive } \\
\text { device }\end{array}$ & $\begin{array}{l}\text { Interpretative } \\
\text { source }\end{array}$ & Tie status & Identity chain & $\begin{array}{l}\text { Similarity } \\
\text { chain }\end{array}$ \\
\hline 1 & $\begin{array}{l}\text { PATIENCE, }<2>\text { had just } \\
\text { returned to the party. }\end{array}$ & $\begin{array}{l}\text { 1. the } \\
\text { (party) }\end{array}$ & $\begin{array}{l}\text {-/in previous } \\
\text { chapters }\end{array}$ & anaphoric & $\begin{array}{l}\text { Patience 1; } \\
\text { Patience 7; }\end{array}$ & $\begin{array}{l}\text { asked 4; } \\
\text { said 8; }\end{array}$ \\
\hline 2 & you will recall, & 2. you & - & exophoric & & \\
\hline 3 & $\begin{array}{l}\text { 'What's happened to your } \\
\text { mistress?' }\end{array}$ & 3. your & 1. PATIENCE & anaphoric & & \\
\hline \multirow[t]{2}{*}{4} & the others asked her. & $\begin{array}{l}\text { 4. the } \\
\text { (others) }\end{array}$ & - & exophoric & & \\
\hline & & her & 3. mistress & anaphoric & $\begin{array}{l}\text { 4-3-1 } \\
\text { Patience }\end{array}$ & \\
\hline 5 & 'Why doesn't she come back & 5. she & 3. mistress & $"$ & & \\
\hline \multirow[t]{2}{*}{6} & and (subject) join us?' & $\begin{array}{l}\text { 6. subject- } \\
\text { ellipsis }\end{array}$ & 5. she & $"$ & $6 e-5-3$ & \\
\hline & & us & 4. others & $"$ & & \\
\hline 7 & 'She hasn't got time,' & 7. She & 6. subject & $"$ & $\begin{array}{l}7-6 e-5-3 \\
\text { mistress }\end{array}$ & \\
\hline 8 & said Patience, & & & & & \\
\hline 9 & laughing. & & & & & \\
\hline
\end{tabular}

\section{The clauses in cohesive chains}

Table 3 is an excerpt from TT2. It lists the ICs and SCs in the text, and illustrates how to identify the clauses with relevant tokens. The relevant tokens in the clauses are labelled bold. The excerpt consists of 9 clauses, which are numbered and listed in two left-most columns. The cohesive devices in the clauses, and the interpretative source of the devices, are listed in left third and fourth columns, so that the cohesive chains can be identified and listed in the right-hand two columns. The subject-ellipsis in clause 6 is taken as part of the identity chain, because it refers to the same entity of the chain '7-6e-5-3', referring to 'the mistress'. There are two identity chains and one similarity chain in this excerpt. The cohesive chains are also bold and shown in the right-hand two columns. The relevant tokens in the chains can be found in 7 clauses; clause 2 and clause 9 only do not contain any relevant token; so the number of clauses with relevant tokens is 7. Thus the proportion of clauses in the cohesive chains is $77.78 \%$ (7 out of 9). With the analysis in the excerpt, all the clauses with relevant tokens in the ST and the TTs are identified, and the results shown in number and ratio in tables.

Table 4 shows the numbers and percentages of clauses in cohesive chains in the ST and TTs. This table displays a clear distinction between the Chinese source text and English target texts in terms of percentages of clauses in the chains. The ST displays the lowest percentage of clauses entering into cohesive chains, while the two TTs show close percentage figures. Both TTs contain a greater percentage of clauses with cohesive chains than the ST does, with 79.82 and $82.39 \%$ as against $69.27 \%$, respectively.

Table 4 Clauses in the cohesive chains in the ST and TTs

\begin{tabular}{llll}
\hline & ST & $\Pi 11$ & $\Pi 2$ \\
\hline Clauses & 2213 & 1915 & 2244 \\
Clauses in the chains & 1516 & 1518 & 1849 \\
percentage & $69.24 \%$ & $79.82 \%$ & $82.39 \%$ \\
\hline
\end{tabular}


Compared with the Chinese ST, more clauses in the English TTs are involved in the construction of cohesive chains, and therefore in the structure of coherence. As a result, the English texts are more explicit than the Chinese text in the construction of texture, because in English TTs more clauses take part in realizing the coherence of the text. To be more specific, around 70\% clauses in the ST link with each other in setting up a grammatically and semantically related net that is taken as the foundation of coherence; whereas almost 80\% clauses in the English TTs are connected to each other. The higher proportion in the English texts reveals that the coherence of the two TTs is realized through more involvement of the clauses than in the ST. In other words, in building up the structure that realizes the coherence of the text, the ST is comparatively implicit while the two TTs are relatively explicit; the ST contains less relevant tokens than the TTs. Therefore, in translation, both translators choose to explicitate some implicit elements in the ST, with more relevant tokens in cohesive chains, to adjust to the target text audience and culture. This is because what was implicit in the source text is no longer apparent in the context of the target texts. Between the two English TTs, the difference in the percentage of clauses with relevant tokens is not significant, being only $2.57 \%$. Some translator personal choices are displayed in the different percentages of clauses in the chains. Given the slight difference of the clauses with relevant tokens in the TT1 and TT2, 79.82 and 82.39\%, respectively, Hawkes' version is more explicit than Yang's in the construction of structure that realizes the coherence of the text. The TT1 exhibits features in between those of the ST and the TT2. Despite the fact that the TT1 is closer to the TT2, the TT1 is still affected by the translator's mother tongue, Chinese. It is probable that the differences between the two TTs are also caused by the different translation purposes and different audiences.

\section{The logical relational features of the clauses in cohesive chains}

As stated before, the collaborative effect of the textual and logical metafunctions can be probed through the logical relations of clauses with relevant tokens. Based on the analysis in the previous section, the percentage of clauses containing relevant tokens is quite different between the Chinese source text and the English target texts. The Chinese ST has a lower percentage of clauses in the cohesive chains than the two English TTs. This section describes in detail the differences in the clauses with relevant tokens in both the ST and TTs.

The clause complexity of clauses represents the logical development of text. It is important in configuring the inter-clausal relations. Both clause simplex and clause complex can represent the status of clause combinations, as whether combined with another clause or not. If combined, each clause in a clause complex is a twodimensional expression of the taxis and logical-semantic type. Take the following sentence as an example: "In the fields just north of our village there stands a small shrine," she said. In the clause complex, clause 1 "In the fields just north of our village there stands a small shrine," and clause 2 she said are in an equal status; and they are indicated with Arabic letters 1 and 2 in terms of taxis. In terms of logico-semantic type, clause 1 is projected by clause 2; and clause 1 is indicated by ' 1 ' and clause 2 is indicated by ' 2 '. An example of the results of the logical relations analysis is shown as below in Table 5. Clause simplex is labelled as null in terms of logical relations. 
Table 5 Clause complex analysis of an excerpt from the $\Pi 1$

\begin{tabular}{|c|c|c|c|c|c|c|c|}
\hline $\mathrm{ID}$ & Clause & \multicolumn{6}{|c|}{ Logical relations } \\
\hline TT1_1_1 & It's as I always say: & & a & & & & \\
\hline TT1_1_2 & When Monk Tripitaka was searching for Buddhist scriptures, & " & $\beta$ & & 1 & $x$ & $\beta$ \\
\hline T1_1_3 & a white horse turned up to carry him; & & & & & & a \\
\hline T1_1_4 & when Liu Zhiyuan was fighting for the empire, & & & + & 2 & $x$ & $\beta$ \\
\hline TT1_1_5 & a melon spirit appeared to give him armour. & & & & & & $a$ \\
\hline T1_2_1 & In the same way, Xifeng has you. & & & & & & \\
\hline
\end{tabular}

Apart from the clause complexity of the clauses with relevant tokens, the study of the calibration of cohesive chains with other metafunctions is fore grounded in this analysis. The cohesive chains realize the semantic continuity and the texture of the text. Through the cohesive chains, both identity and similarity, the plot is continuous, with the strings of events and characters under a certain context, in narrative texts. Since the study of cohesive chains reveals the continuity of the text, such a study can be seen as the basis for further investigation into the textual coherence of a text. As stated in the framework, the realization of coherence at the lexicogrammatical level is reflected in the analysis from the perspectives of the logical and textual metafunctions. In addition, the combination of the logical relations and cohesive chains demonstrates how the semantic continuity of the text is realized grammatically via the progression of the clauses. The different logical relations may have different functions in the creation of the text. The coherence of the text can be expressed by the lexicogrammatical patterns of the combination of the logical and textual.

The example in Table 6 is an excerpt from the TT2. There is an identity chain referring to 'Lucky, the maid' throughout the text, and this chain is labelled as '9-8-6-5-4-3-2-1'; only clause 7 is not involved in the cohesive chain. The bold words are the relevant tokens in the cohesive chain. From the excerpt, 1 clause simplex, 8 hypotactic clauses, and 3 paratactic clauses are in the cohesive chain. In terms of logicosemantic type, one idea and two enhancing clauses are in the cohesive chain. Thus, the proportions of each type of clause in the chains can be calculated. With this method exemplified, all the texts are investigated in respect of clause types involved in the cohesive chains.

Table 6 Clause complex analysis with cohesive chains of an excerpt from the TT2

\begin{tabular}{|c|c|c|c|c|c|c|}
\hline Clause ID & Clause & \multicolumn{5}{|c|}{ Logical relations } \\
\hline 1 & $\begin{array}{l}\text { Lucky was, of course, the maid who had once } \\
\text { turned back to look at Yu-cun when they were living at the house in Soochow. }\end{array}$ & & & & & \\
\hline 2 & She could scarcely have foreseen at the time & & a & & & \\
\hline 3 & what singular good fortune that one glance would procure for her. & ' & $\beta$ & & & \\
\hline 4 & But she was destined to be doubly fortunate. & & & & & \\
\hline 5 & She had not been with Yu-cun more than a year & & 1 & & a & \\
\hline 6 & when she gave birth to a son; & & & & $\beta$ & \\
\hline 7 & and a mere six months later Yu-cun's first wife died, & & 2 & & a & \\
\hline 8 & whereupon Lucky was promoted to fill her place & & & & $\beta$ & 1 \\
\hline 9 & and (subject-ellipsis) became Her Lady ship. & & & & & 2 \\
\hline
\end{tabular}


Therefore, the clauses containing relevant tokens show the lexicogrammatical patterns of the text in construing coherence. The ratio of each logical relation can show the role that these clauses play, and how they are used in the construction of the Chinese source text and the English target texts.

\section{The clause types in the cohesive chains in the texts}

The clauses entering into the cohesive chains can be considered as contributing to the formation of cohesion, and also to the texture of the text, in terms of their complexity, taxis, and also logico-semantic type. The features that the clauses with relevant tokens display show the lexicogrammatical realization patterns of the logical and textual metafunctions together in a coherent text.

Figure 2 shows the numbers and percentages of clause simplexes and clause complexes with relevant tokens of the Chinese source text and its two English translations. In general, Fig. 2 shows a clear difference between the ST and the TTs. The two TTs show a similar inclination for involving the different types of clauses in the cohesive chains. Firstly, the percentages of clause simplexes involved in the cohesive chains in the three texts differ significantly, especially between the Chinese source text and the two English target texts. The ST contains the least clause simplexes in the cohesive chains: 81 clause simplexes only form about $4.01 \%$ of all the clauses in chains. In the two TTs, both the number and proportion of clause simplexes is more than those in the ST: 282 make $15.55 \%$ and 321 make $14.29 \%$, for the TT1 and TT2, respectively, of all the clauses in the chains in each text. Secondly, clause complexes are a higher percentage than simplexes in the cohesive chains. In terms of the taxis of those clause complexes, the Chinese source text is also distinguished from the two English target texts: the ST uses the most paratactic clauses in the cohesive chains, with 1176 paratactic clauses making about $60.81 \%$ of all the clauses with relevant tokens; however, in the two TTs, the numbers are 840 and 962 for the TT1 and TT2, making around 46.31 and $42.83 \%$ in all the clauses in the cohesive chains, respectively. The hypotactic clauses in the cohesive chains show a different trend compared to the use of paratactic clauses in the three texts: the ST and the TT1 are closer to each other in terms of the percentage of hypotactic clauses with relevant tokens, with 35.01 and $38.15 \%$, respectively; while the TT2 has the most hypotactic clauses in cohesive chains, 963 , making $42.88 \%$ of the total.

The different percentages of each type of clause with relevant tokens show the trends of the Chinese text and the two English texts in using different kinds of clause in the construction of the cohesive chains, and therefore, in building up the threads of coherence in the text. The percentages of the clause simplexes and the taxis types of clause

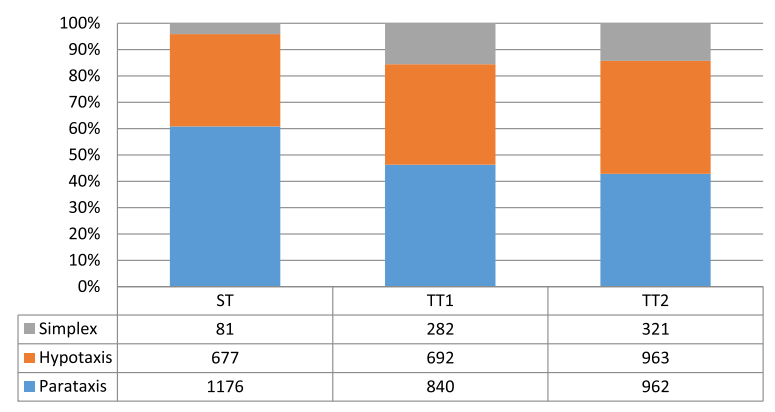

Fig. 2 Clause types in the chains in the three texts 
complexes with relevant tokens reveal: that Chinese source text relies more on clause complexes, and especially on paratactic clauses in the construction of cohesive chains; and that the two English target texts show more preference for clause simplexes than the ST. Despite there being more clause simplexes in the TT1, the TT1 displays features more alike to the ST than to the TT2.

The two translators have their own preferences for using different types of taxis in the construction of cohesive chains; and the analysis of their use of taxis reveals the different degree of involvement of taxis in building up the semantic threads of the text.

\section{The logico-semantic type in the cohesive chains in the three texts}

In addition to taxis, logico-semantic type also needs to be probed in terms of involvement in cohesive chains.

Figure 3 displays the composition of both the Chinese source text and the two English target texts in respect of projecting and expanding clauses. In all the three texts, expanding clauses show an increasing trend from the ST to the TT2; while the projecting clauses accordingly show a decreasing trend. Expansion makes up 79.3\% of the ST, and decreases to 76.02 and $74.74 \%$ in the TT1 and TT2, respectively. Conversely, projection increases from $20.7 \%$ in the ST to 23.98 and $25.26 \%$ in the TT1 and TT2, respectively. The TT1 and TT2 display a conformable trend in their use of expansion and projection, with only about $1 \%$ discrepancy between the two texts.

In translation, projecting clauses with relevant tokens have a higher ratio than in the ST, even though the numbers of those clauses in the three texts vary. The two translators display a similar trend of making projecting clauses more explicit in the TTs than in the ST.

To see the use of the sub types of logico-semantic type in detail, more data analyses are shown in Tables 7 and 9 in terms of Projection and Expansion.

Table 7 lists the two types of projection in the three texts. The ST distinguishes itself from the two TTs by using much more locution and fewer of idea. It uses the least percentage of idea (13.85\%), and accordingly the most locution (86.15\%). The results of Fig. 3 show that the TT1 makes the projecting clauses more implicit, while the TT2 makes them more explicit, in the cohesive chains, compared to the ST. However, within these projecting clauses, the two TTs show a similar trend, of 23.73 and $26.09 \%$ (the TT1 and TT2, respectively) for idea and 76.27 and $73.91 \%$ for locution, in each text.

In translation, the transference of idea in the target texts is made more explicit than in the ST. Hence, it can be inferred that, in the translation of the TT2, Hawkes makes the projecting clauses more explicit, in addressing the semantic sequence of the text;

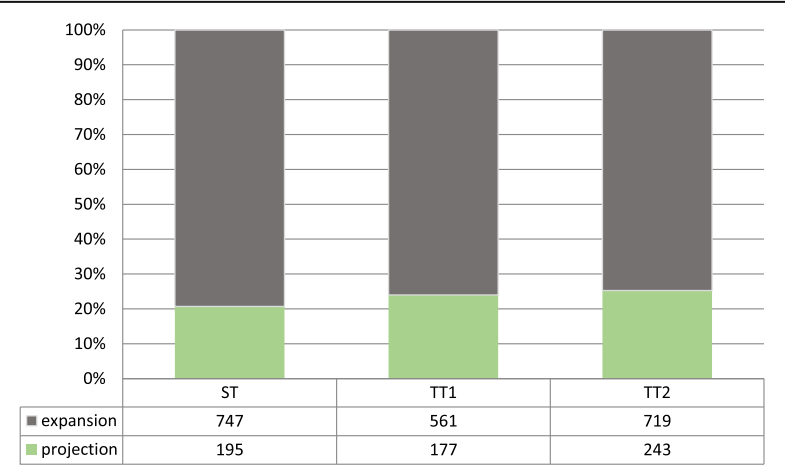

Fig. 3 Number of clauses in the chains in terms of logico-semantic type in the three texts 
Table 7 Comparison of types of Projection

\begin{tabular}{lllllll}
\hline & ST & \multicolumn{3}{c}{ T1 } & \multicolumn{1}{c}{} \\
\hline Locution & 168 & $86.15 \%$ & 135 & $76.27 \%$ & 187 & $73.91 \%$ \\
Idea & 27 & $13.85 \%$ & 42 & $23.73 \%$ & 66 & $26.09 \%$ \\
\hline
\end{tabular}

and he also appears to have added certain referencing items in the clauses to indicate the projection.

In Table 8, the ST does not contain an identity chain for 'you', referring to Patience in the text. However, in the TT2, the identity chain is made explicit: only clause TT2_1_2 is not involved in the chain. Within the clauses with relevant token, 'you', clause TT2_2_3 is projected by an 'idea'. In translation, the projection is made explicit.

Aside from the Projection, the three texts also display differences in Expansion, which consists of three subcategories, elaboration, extension and enhancement. Table 9 shows the results of the three subcategories of Expansion in the three texts.

In general, the ST and the TTs show both similarities and differences. Firstly, the most distinctive feature is that extending clauses are in the highest percentage in the TT1: about $38.32 \%$ in the TT1, which is much more than the 32.96 and $28.92 \%$, in the TT2 and the ST, respectively. Secondly, the ST uses the most 'elaboration', with 75 elaborating clauses making about $10.04 \%$ of the total. This percentage decreases to 8.02 and $7.65 \%$ in the TT1 and TT2, respectively. Thirdly, the ST and TT2 show similar preferences for using enhancing clauses in the chains, with about $60 \%$ for both.

Table 8 Clause complex and cohesive chain analysis of an excerpt

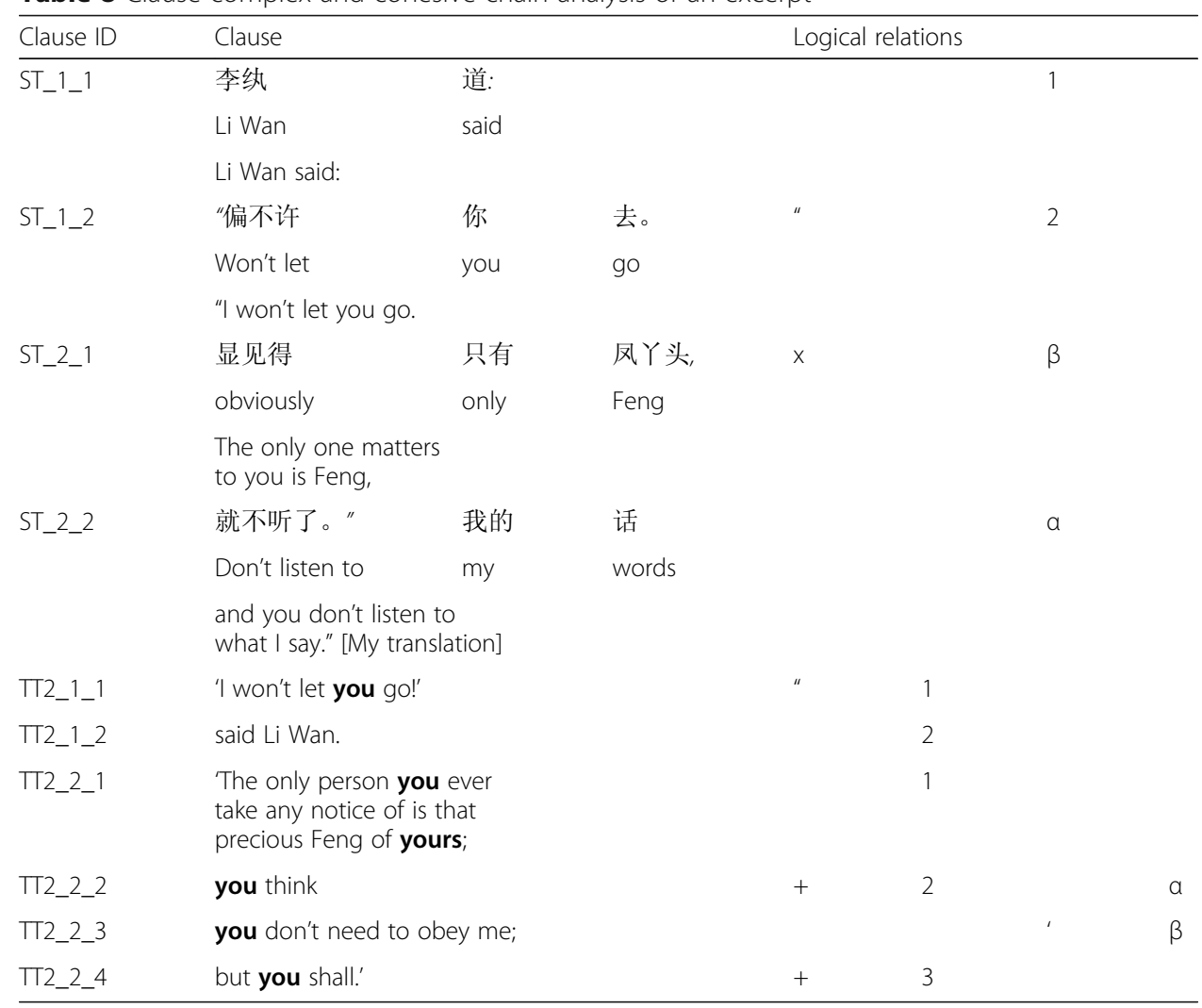


Table 9 Comparison of Expansion in the three texts

\begin{tabular}{lllllll}
\hline & ST & \multicolumn{3}{c}{ TT1 } \\
\hline Enhancement & 456 & $61.04 \%$ & 301 & $53.65 \%$ & 427 & $59.39 \%$ \\
Extension & 216 & $28.92 \%$ & 215 & $38.32 \%$ & 237 & $32.96 \%$ \\
Elaboration & 75 & $10.04 \%$ & 45 & $8.02 \%$ & 55 & $7.65 \%$ \\
\hline
\end{tabular}

In the translation of expansion, the percentages in the TT1 and the TT2 indicate that the two translators choose different approaches to dealing with 'enhancement' and 'extension': Yang prefers to use more 'extension' than Hawkes. In addition, extending clauses have more importance in shaping the cohesive structure of the TT1. In general, Hawkes uses similar proportions of each subtype of expanding clauses in the cohesive chains in comparison to the source text.

\section{Findings}

The clauses containing relevant tokens in the cohesive chains reflect the lexicogrammatical features of the Chinese source text and English target texts in construing the coherence of the text. The logical environment of the cohesive chains is manifested by the clause complexity and taxis and logico-semantic types in clause complexes, revealing not only the methods of realizing coherence in the ST and TTs but also the different translators' styles. Style is a matter of patterning, as "it involves describing preferred or recurring patterns of linguistic behaviour, rather than individual or one-off instances of intervention" (Baker 2000, p. 245). The percentage of each clause type exhibits the patterns of choice of different text producers. These patterns of choice (whether these choices are conscious or subconscious), rather than individual choice in isolation (Baker 2000, p. 246), can reflect the styles of text producers and also the reasons behind the choices.

The features in the ST and TTs in this research tell us: not only what is in the text but also what is in the language; what is specific of the translator; and, furthermore, the cultural and ideological reasons behind the patterns of different texts and translators. To better understand the patterns of the logical and textual metafunctions in the construction of a coherent text, the interweaving of clause and cohesive chains at lexicogrammatical level in the above analysis can be summarised, to give a general view. In general terms, the clauses in the cohesive chains in the Chinese source text and the two English target texts display some similarities as well as differences, which can be stated as follows:

From the logical metafunctional perspective, the similarities of the clauses in the cohesive chains among the ST, the TT1 and the TT2 are mainly in the taxis:

a) More paratactic clauses contain relevant tokens than hypotactic clauses do in the ST and the TT1; whereas the amount of hypotaxis outweighs parataxis in the TT2. The clauses with relevant tokens reflect the features of the language itself. In translation, the translators are also affected by the features of their first language in construing the texture of the text.

b) The percentage of both hypotactic and paratactic clauses involved in the cohesive chains in the TT1 is in between those of the ST and the TT2. This shows that the TT1 exhibits characteristics of both the Chinese and English languages. 
There is no specific rule in the use of clauses in the cohesive chains, from the perspective of logico-semantic type. Each text has shown its unique trend and characteristics with regard to 'projection' and 'expansion'.

a) In English target texts, there are more instances of 'idea' than in the Chinese source texts. Despite the fact that the two TTs display similar percentage of 'locution', the TT2 uses more 'locution' than the ST and TT1.

b) For the expanding clauses in the cohesive chains, elaborating clauses are the least favoured, while enhancing clauses are the most favoured. The TT2 is closer to the ST than the TT1 to the ST in this respect.

The lexicogrammatical features in the texts imply the purpose of the author and the translators of the literary text. The writer of the Chinese novel builds up a coherent text with comparatively implicit ways of realizing coherence; while the translators create more explicit English target texts in the manifestation of coherence. One possible reason for this difference is that the Chinese readers do not need as much explicit coherence patterning to understand the context of the text; while the English readers need much more explicit expression of the connections of the segments of the text to build up the cultural context of the texts. Another reason for this difference might be that the distance between the text and the reader, for the ST and the TTs, is different. The Chinese readers are within the same context of culture as the source text; whereas the English readers are within a different context of culture. Therefore, the differences and distances reflected in the texts are shown via the similarities and differences of the coherence realization, as revealed in the analyses presented in this research.

It is hoped that this research will be able to shed light on the study of coherence in translation from systemic functional linguistic perspective.

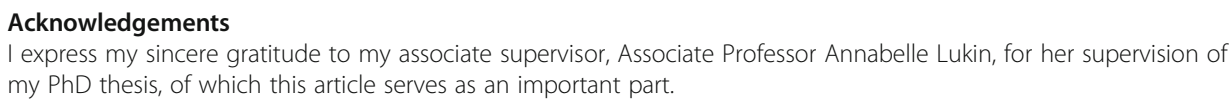

\section{References}

Baker, M. 2000. Towards a methodology for investigating the style of a literary translator. Target 12(2): 241-66. Beaugrande, R.d., and W. Dressler. 1981. Introduction to Text linguistics. New York: Longman Inc.

Campbell, K.S. 2013. Coherence, continuity, and cohesion: theoretical foundations for document design. London: Routledge.

Danes, F. 1974. Functional sentence perspective and the organization of the text. In Papers on functional sentence perspective, 106-28.

Eggins, S. 1994. An introduction to systemic functional grammar. London: Pinter.

Garrod, S., and G. Doherty. 1995. Special determinants of coherence in spoken dialogue. In Focus and coherence in discourse processing, ed. G. Rickheit and C. Habel (Hgg.), 97-114.

Giora, R. 1985. Notes towards a theory of text coherence. Poetics Today 6(4): 699-715. 
Halliday, M.A.K. 1984. Language as code and language as behaviour: a systemic-functional interpretation of the nature and ontogenesis of dialogue. The Semiotics of Culture and Language 1: 3-35.

Halliday, M.A.K. 1994. Functional grammar. London: Edward Arnold.

Halliday, M.A.K. 2003. On the "architecture" of human language. In On language and linguistics, vol. 3, 15-6. London and New York: Equinox.

Halliday, M.A.K., and R. Hasan. 1976. Cohesion in English. London: Longman.

Halliday, M.A.K., and R. Hasan. 1985 [1989]. Language, context, and text: aspects of language in a social-semiotic perspective. Halliday, M.A.K., and C.M. Matthiessen. 2004. An introduction to functional grammar.

Harabagiu, S.M. 1999. From lexical cohesion to textual coherence: a data driven perspective. International Journal of Pattern Recognition and Artificial Intelligence 13(02): 247-65.

Hasan, R. 1978. Text in the systemic-functional model. Current Trends in Textlinguistics 2: 229-45.

Hasan, R. 1984. Coherence and cohesive harmony, Understanding reading comprehension: Cognition, language and the structure of prose, 181-219.

Hasan, R. 1985. Linguistics, Language and Verbal Art. Geelong: Deakin University Press.

Hatim, B, I. Mason. 1990. Discourse and the translator. London and New York: Longman.

Hawkes, D. 1973. The Story of the Stone: the Golden Days, vol. 1. Great Britain: Penguin Group.

Huang, G. 1988. 语篇分析概要[Essentials of Text Analysis]. 长沙[Changsha]: 湖南教育出版社[Hunan Educational Publishing House].

Kintsch, W., and T.A. Van Dijk. 1978. Toward a model of text comprehension and production. Psychological Review 85(5): 363.

Knott, A., and R. Dale. 1994. Using linguistic phenomena to motivate a set of coherence relations. Discourse Processes 18(1): 35-62.

Lorentz, G. 1999. Learning to Cohere: causal links in native vs. non-native argumentation writing, Coherence in spoken and written discourse, 55-75.

Lukin, A. 2013. What do texts do? The context-construing work of news. Text \& Talk 33(4-5): 523-51.

Mann, W.C., and S.A. Thompson. 1987. Rhetorical structure theory: a theory of text organization. DTIC Document.

Mann, W.C., C. Matthiessen, and S.A. Thompson. 1989. Rhetorical structure theory and text analysis. Information Science Institute.

Neubert, A., and G.M. Shreve. 1992. Translation as text. Kent: Kent State University Press.

Reinhart, T. 1980. Conditions for text coherence. Poetics Today 1(4): 161-80.

Seidlhofer, B., and H. Widdowson. 1999. Coherence in summary: the contexts of appropriate discourse, Paper presented at the Coherence in Spoken and Written Discourse: How to Create it and how to Describe it: Selected Papers from the International Workshop on Coherence, Augsburg, 24-27 April 1997.

Taboada, M.T. 2004. Building coherence and cohesion: task-oriented dialogue in English and Spanish, vol. 129. Amsterdam: John Benjamins Publishing.

Tanskanen, S.K. 2006. Collaborating towards coherence: lexical cohesion in English discourse. Amsterdam: John Benjamins Publishing.

Ted J.M. Sanders, Leo G.M. Noordman, (2000) The Role of Coherence Relations and Their Linguistic Markers in Text Processing. Discourse Processes 29(1):37-60

Tierney, R.J., and J.H. Mosenthal. 1983. Cohesion and textual coherence. Research in the Teaching of English, 215-29.

Van Dijk, T.A. 1977. Semantic macro-structures and knowledge frames in discourse comprehension, Cognitive processes in comprehension, 3-32.

Van Dijk, T.A. 1985. Semantic discourse analysis. Handbook of Discourse Analysis 2: 29-56.

Van Dijk, T.A., and W. Kintsch. 1983. Strategies of discourse comprehension. New York: Academic Press New York.

Werth, P. 1984. Focus, coherence and emphasis. New York: Taylor \& Francis.

Widdowson, H.G. 1978. Teaching language as communication. Oxford: Oxford University Press.

Widdowson, H.G. 2007. Discourse analysis, vol. 20. Oxford: Oxford University Press Oxford.

Wolf, F., and E. Gibson. 2006. Coherence in natural language: data structures and applications. Philadelphia: The MIT Press.

Yang, X., and G. Yang. 1994. A Dream of Red Mansions. Beijing: Foreign Languages Press.

Zhang, D. 1999. 语篇连贯研究纵横谈 [A research on textual coherence]. 外国语 [Journal of Foreign Languages] 6: 24-31.

Zhang, D. 2012. New Developments in the Theory of Discourse Analysis and Its Application. Beijing: Foreign Language Teaching and Research Press.

\section{Submit your manuscript to a SpringerOpen ${ }^{\circ}$ journal and benefit from:}

- Convenient online submission

Rigorous peer review

- Immediate publication on acceptance

- Open access: articles freely available online

- High visibility within the field

Retaining the copyright to your article

Submit your next manuscript at $\gg$ springeropen.com 